\title{
Endothelial Dysfunction in Femoral Artery of the Hypertensive Rats Is Nitric Oxide Independent
}

\author{
A. PÚZSEROVÁ ${ }^{1}$, J. KOPINCOVÁ ${ }^{1,2}$, P. SLEZÁK ${ }^{1}$, P. BALIŠ ${ }^{1}$, I. BERNÁTOVÁ $^{1}$ \\ ${ }^{1}$ Institute of Normal and Pathological Physiology, Centre of Excellence for Examination of \\ Regulatory Role of Nitric Oxide in Civilization Diseases, Slovak Academy of Sciences, Bratislava, \\ Slovak Republic, ${ }^{2}$ Department of Physiology, Jessenius Faculty of Medicine, Comenius University, \\ Martin, Slovak Republic
}

Received January 24, 2013

Accepted May 2, 2013

On-line July 17, 2013

\section{Summary}

This study examined nitric oxide (NO) production, oxidative load and endothelium-dependent relaxation (NO-dependent and NOindependent) in adult male borderline hypertensive (BHR) and spontaneously hypertensive (SHR) rats as compared to normotensive Wistar-Kyoto (WKY) rats. Systolic blood pressure (BP) was determined by tail-cuff. NO production was determined by conversion of $\left[{ }^{3} \mathrm{H}\right]$-L-arginine. Conjugated dienes (CD) and concentrations of thiobarbituric acid-reactive substances (TBARS) were measured for assessment of oxidative load. Vascular function was investigated in rings of the femoral artery (FA) using a wire myograph. BP of WKY, BHR and SHR was 106 \pm 2 , $143 \pm 3$ and $191 \pm 3 \mathrm{~mm} \mathrm{Hg}$, respectively ( $p<0.01$ for each). Significant left ventricle (LV) hypertrophy and elevated levels of $C D$ and TBARS in the LV were present in BHR and SHR as compared to WKY. NO production was elevated significantly in the aorta of BHR and SHR vs. WKY as well as in the LV of SHR vs. WKY. Acetylcholine (ACh)-induced relaxation of the FA was reduced significantly in both BHR and SHR vs. WKY. The NOdependent component of $\mathrm{ACh}$-induced relaxation had increasing tendency in hypertensive groups and it correlated positively with $\mathrm{BP}$. The NO-independent component of vasorelaxation was reduced significantly in BHR and SHR vs. WKY and it correlated negatively with BP. In conclusion, the results showed that endothelial dysfunction in the experimental model of borderline hypertensive and hypertensive rats is NO-independent. The results suggest that borderline hypertension represents a risk of other cardiovascular disorders which is qualitatively similar to that of fully developed hypertension.

\section{Key words}

Acetylcholine - Borderline hypertension - Endothelium • SHR • Vascular reactivity

\section{Corresponding author}

Angelika Puzserova, Institute of Normal and Pathological Physiology, Slovak Academy of Sciences, Sienkiewiczova 1, 81371 Bratislava, Slovak Republic. Fax: +421-2-52968516. E-mail: angelika.puzserova@savba.sk

\section{Introduction}

Chronic hypertension is generally considered to be a risk factor of several cardiovascular diseases. However, prehypertension is not a disease category (Chobanian et al. 2003) and relatively little attention has been paid to prevention of cardiovascular risk resulting from marginal elevation of blood pressure (BP) in adult individuals. Although the vascular mechanisms involved in prehypertension and hypertension are not well-defined, there are studies suggesting the involvement of endothelial dysfunction (ED) in conduit and resistance arteries in association with altered nitric oxide (NO) production and oxidative stress, which may significantly contribute to the pathogenesis of hypertension by increasing peripheral vascular resistance.

Observations in spontaneously hypertensive rats (SHR), a widely used experimental model of human essential hypertension (Yamori and Okamoto 1973, Pintérová et al. 2011, Kuneš et al. 2012), showed considerable differences related to ED (Vapaatalo et al. 
2000, Török 2008, Gündüz et al. 2011). As shown in the literature, ED in SHR depends on several factors including age, artery size and methodological approaches (Bernatova et al. 2009). Since hypertension in SHR occurs already at juvenile age (about 5-8 weeks), it is impossible to examine metabolic and vascular alterations in the prehypertensive period in adult $(12+$ week-old) SHR. For this reason, borderline hypertensive rats (BHR) are more suitable for investigating the early stage of hypertension development in adulthood, which is obvious in the human population, and needs to be better understood.

Borderline hypertensive rats, an experimental model of human prehypertension and early stage hypertension, can be produced by mating spontaneously hypertensive dams with normotensive sires (Lawler et al. 1980, Fuchs et al. 1998, Bernatova et al. 2007, Pechánová et al. 2009). Resting systolic BP of adult offspring in the first-generation is in the range 130-150 mm Hg (Sanders and Lawler 1992, Mansi and Drolet 1997, Bernatova et al. 2007), which allows investigating the vascular function in adult animals with mild elevation of blood pressure.

In general, ED is characterized by alterations in the production and/or bioavailability of endotheliumderived relaxing factors (EDRFs) and endotheliumderived constricting factors (EDCFs) (Török 2008, Vanhoutte 2009). The functional status of the endothelium is usually tested by the acetylcholine (ACh) test in isolated pre-constricted arteries. ACh-induced relaxation results from stimulated release of at least three different vasodilating agents from the endothelial cells nitric oxide (NO), prostacyclin $\left(\mathrm{PGI}_{2}\right)$, and endotheliumderived hyperpolarizing factor(s) (EDHFs) (Fujimoto and Fujimoto 2001, Stankevicius et al. 2003, Gündüz et al. 2011). NO seems to be the most powerful vasorelaxing factor, however the extent of NO-dependent relaxation depends on the size of the artery. The greatest NOdependency of vasorelaxation was observed in the aorta, while the role of NO is much smaller in the regulation of endothelial function in the small resistant arteries where EDHFs seem to be more important (Shimokawa et al. 1996, Török 2008).

In this study we investigated vascular function (contractile responses and vasorelaxation including its NO-dependent and NO-independent components) in the femoral artery as well as the oxidative load and NO production in selected tissues of normotensive, borderline hypertensive and spontaneously hypertensive rats in order to determine the role of $\mathrm{NO}$ and the seriousness of vascular changes in conditions of borderline hypertension in adulthood.

\section{Methods}

Animals

All rats used in the present study were born in our certified animal facility (Institute of Normal and Pathological Physiology SAS) in order to maintain the same environmental background of all animals. Adult, 22-week old males of Wistar-Kyoto (WKY, negative control), BHR and SHR (positive control) were used in this study ( $\mathrm{n}=10$ each). BHRs were the first filial offspring of SHR dams and normotensive WKY sires. Rats were housed in groups of 5 rats per cage (35/55/20 $\mathrm{cm})$, each genotype separately, in an air-conditioned room at constant temperature $\left(22-24^{\circ} \mathrm{C}\right)$ and humidity (45-60\%) at a 12:12-h light/dark cycle (06:00-18:00 h lights on) and maintained on a standard pellet diet and tap water ad libitum. Drinking water consumption was measured in each group from the age of 12 weeks (beginning of adulthood) to 22 weeks of age (end of experiment). All procedures used were in accordance with the EU Directive 2010/63/EU and they were approved by the State Veterinary and Food Administration of the Slovak Republic.

\section{Experimental design}

Twenty-two-week-old Wistar-Kyoto, borderline hypertensive and spontaneously hypertensive rats were killed by decapitation after a brief $\mathrm{CO}_{2}$ anesthesia between 7:30 and 9:30 AM. Wet mass of the left heart ventricle (LVM) and body mass (BM) were determined for calculation of the relative left ventricular mass (LVM/BM) to evaluate the degree of cardiac hypertrophy.

\section{Blood pressure and heart rate}

Systolic blood pressure (BP) and heart rate (HR) were determined non-invasively in conscious rats by tailcuff plethysmography (using the Statham Pressure Transducer P23XL, Hugo Sachs, Germany). One week before experimentation, the rats were handled and accustomed to the tail-cuff procedure of blood pressure recording in three independent sessions (Durante et al. 2010). Blood pressure and heart rate were determined between 9:00-12:00 $\mathrm{h}$ and were calculated as the average value of 4-5 successive measurements (Puzserova et al. 2013). 


\section{Assessment of vascular reactivity by wire myograph}

Femoral arteries (FA) were carefully dissected, immediately immersed in modified cold physiological salt solution (PSS) and cleaned of adipose or connective tissue. Arteries were then cut into segments $(1.33 \pm 0.04$ $\mathrm{mm}$ long) and mounted as ring-shaped preparations in the Mulvany-Halpern style small vessel wire myograph chamber (Dual Wire Myograph System 410A, DMT A/S, Aarhus, Denmark) to determine the vascular reactivity during isometric conditions as described elsewhere (Mulvany and Halpern 1977). After mounting in oxygenated $\left(\begin{array}{llllll}5 \% & \mathrm{CO}_{2}, & 95 \% & \mathrm{O}_{2} & \text { mixture }\end{array}\right)$ PSS (composition in mmol/l: $\mathrm{NaCl} 118.99, \mathrm{KCl} 4.69$, $\mathrm{NaHCO}_{3} \quad 25, \quad \mathrm{MgSO}_{4} .7 \mathrm{H}_{2} \mathrm{O}$ 1.17, $\mathrm{KH}_{2} \mathrm{PO}_{4} \quad 1.18$, $\mathrm{CaCl}_{2} .2 \mathrm{H}_{2} \mathrm{O} 2.5, \mathrm{Na}_{2}$ EDTA 0.03, glucose 5.5), pH 7.4, at $37{ }^{\circ} \mathrm{C}$, a standardized computer-assisted normalization procedure was performed to set the pre-tension of the arteries. The arteries were set to a circumference equivalent to $90 \%$ of that which they would have at a transmural pressure of $100 \mathrm{~mm} \mathrm{Hg}(90 \%$ of the normalized inner circumference). The change in wall tension (active wall tension) was calculated as measured force divided by the double segment length and expressed in $\mathrm{mN} / \mathrm{mm}$. Resting wall tension (which arises from the properties of the passive elements in the vascular wall) was also determined after the normalization procedure (Mulvany and Halpern 1977).

\section{Femoral artery reactivity}

Before the start of the normalization procedure, the vessels were allowed to stabilize in PSS for $30 \mathrm{~min}$. The experimental protocol consisted of the following steps: $45 \mathrm{~min}$ after normalization, PSS was changed to KPSS in which $\mathrm{NaCl}$ was exchanged for an equimolar concentration of $\mathrm{KCl}$ (in whole KPSS $125 \mathrm{mmol} / \mathrm{l}$ for $2 \mathrm{~min}$ ) followed by wash-out with PSS to baseline (15 min). After noradrenaline (NA) addition (10 $\mu \mathrm{mol} / \mathrm{l}$, maximal stimulation, waiting to plateau) and wash-out (PSS, $20 \mathrm{~min}$ ), pre-constriction was achieved by serotonin (5-hydroxytryptamine, $1 \mu \mathrm{mol} / \mathrm{l}$, waiting to plateau). When the contraction of the femoral artery to serotonin reached a steady state, increasing concentrations of the vasodilator acetylcholine (ACh, 0.001 to $10 \mu \mathrm{mol} / \mathrm{l}$ ) were added in cumulative manner to perform endothelium-dependent concentration-response curves (Fujimoto and Fujimoto 2001). When the concentration-relaxation curve was completed, the drugs were washed-out (PSS, $20 \mathrm{~min}$ ) and the same experiment was repeated in presence of $\mathrm{N}^{\mathrm{G}}$-nitro-L-arginine methyl ester (L-NAME, nitric oxide synthase inhibitor, $300 \mu \mathrm{mol} / \mathrm{l}$ ) after a 25 -min pre-incubation period. In the presence of L-NAME, we could preclude ACh-induced NO release, the curve thus represented L-NAME-resistant (i.e. NO-independent) component of ACh-induced relaxation. When concentration-response curve for $\mathrm{ACh}$ was completed, drugs were wash-out (PSS, $30 \mathrm{~min}$ ), and the nitric oxide donor sodium nitroprusside (SNP, 0.001 to $10 \mu \mathrm{mol} / \mathrm{l}$ ) was added by cumulative manner to the pre-constricted arteries (serotonin, $1 \mu \mathrm{mol} / \mathrm{l}$ ).

After the following wash-out (PSS, $20 \mathrm{~min}$ ), the femoral artery rings were stimulated with high concentration of $\mathrm{K}^{+}(125 \mathrm{mmol} / \mathrm{l})$ in depolarizing solution to induce maximal contraction (PSS was changed to KPSS) and then left to achieve plateau. The maximal tension achieved with depolarizing solution was set as $100 \%$ to express the active tension generated by different vasoconstrictors (Puzserova and Bernatova 2010).

The NO-dependent (i.e. L-NAME-sensitive) component of endothelium-dependent relaxation was calculated as the difference between ACh-induced relaxation before and after acute L-NAME pre-treatment (Paulis et al. 2008, Puzserova and Bernatova 2010) and expressed as area under the curve (AUC, in arbitrary units - a.u.) based on the individual concentrationresponse curves (Puzserova and Bernatova 2010). The extent of vasorelaxation was expressed in relative values as the percentage of the initial contraction induced by serotonin as well as in absolute values as agonist-induced wall tension decrease ( $\mathrm{mN} / \mathrm{mm}$ ) (Webb et al. 1987, Hansen and Nedergaard 1999, Líšková et al. 2011). Vasoconstrictions were determined as the maximal tension and they were expressed as active wall tension in $\mathrm{mN} / \mathrm{mm}$. Responses to each drug concentration were always allowed to stabilize before addition of a subsequent dose of the same drug or of another drug (Asano et al. 1982, Webb et al. 1987).

All chemicals used were purchased from SigmaAldrich (Germany), except noradrenaline hydrogenotartras (Zentiva, Czech Republic). NA was prepared daily. All drugs were dissolved in distilled water and concentrations were expressed as final concentration in the myograph chamber.

\section{Oxidative stress markers}

For assessment of oxidative load, conjugated dienes (CD) and concentrations of thiobarbituric acidreactive substances (TBARS) were measured in the left ventricle (LV), as described previously (Hu et al. 1989), 
with some modifications.

To determine TBARS, $1 \mathrm{ml}$ of tissue homogenate of the left ventricle $(10 \% \mathrm{w}: \mathrm{v}$, in $1.15 \%$ $\mathrm{KCl}$ in $0.01 \mathrm{~mol} / \mathrm{l}$ phosphate buffer, $\mathrm{pH} 7.4$ ) was added to $2 \mathrm{ml}$ of $7.5 \%$ trichloroacetic acid and mixed. After centrifugation at $1000 \mathrm{~g}$ for $10 \mathrm{~min}, 1 \mathrm{ml}$ of the supernatant was added to $0.5 \mathrm{ml}$ of $0.7 \%$ 2-thiobarbituric acid and incubated in a water bath at $100{ }^{\circ} \mathrm{C}$ for $10 \mathrm{~min}$. After cooling, TBARS were measured at $532 \mathrm{~nm}$ (GBC UV/VIS 911 A). An extinction coefficient of $156000 \mathrm{~mol}^{-1} \cdot 1 . \mathrm{cm}^{-1}$ was used for calculation of the results.

CD were determined from the same tissue homogenates as TBARS. Homogenate $(0.4 \mathrm{ml})$ was mixed with $1.5 \mathrm{ml}$ chloroform:methanol (1:2) for $1 \mathrm{~min}$, and $0.5 \mathrm{ml}$ of chloroform was added and mixed for $30 \mathrm{~s}$. Afterwards, $0.5 \mathrm{ml}$ of deionized water was added and mixed for additional $30 \mathrm{~s}$. After centrifugation for $10 \mathrm{~min}$ at $1000 \mathrm{~g}, 0.5 \mathrm{ml}$ of the chloroform (lower) layer was removed and dried under nitrogen. The lipid was dissolved in $2 \mathrm{ml}$ of cyclohexane, and conjugated dienes were measured at $233 \mathrm{~nm}$ using an extinction coefficient of $27000 \mathrm{~mol}^{-1} \cdot 1 \cdot \mathrm{cm}^{-1}$.

All chemicals used were purchased from SigmaAldrich (Germany) and Merck Chemicals (Germany).

\section{Nitric oxide synthase activity}

Total NO synthase (NOS) activity was measured in tissue homogenates of the aorta and left ventricle $(200 \mathrm{mg} / \mathrm{ml})$ by determination of $\left[{ }^{3} \mathrm{H}\right]-\mathrm{L}$-citrulline formation from $\left[{ }^{3} \mathrm{H}\right]$-L-arginine, as described previously (Púzserová et al. 2006, Puzserova et al. 2013) and expressed as $\mathrm{pmol} / \mathrm{min} / \mathrm{mg}$ of tissue proteins as determined by the Lowry method (Lowry et al. 1951). Briefly, crude homogenates of the aorta and LV containing $200 \mathrm{mg}$ of wet tissue per $1 \mathrm{ml}$ of homogenization solution containing $50 \mathrm{mmol} / \mathrm{l}$ Tris- $\mathrm{HCl}$, pH 7.4 and $1 \%$ Protease Inhibitor Cocktail (Sigma, Germany) were centrifuged at $10000 \mathrm{~g}$ for $10 \mathrm{~min}$ at $4{ }^{\circ} \mathrm{C}$. After centrifugation, $50 \mu \mathrm{l}$ of supernatant was incubated in the presence of $10 \mu \mathrm{mol} / 1\left[{ }^{3} \mathrm{H}\right]$-L-arginine (MP Biomedicals, USA, 50 Ci $/ \mathrm{mmol}$ ), $5 \mu \mathrm{g} / \mathrm{ml}$ calmodulin, $\quad 0.5 \quad \mathrm{mmol} / 1 \quad \beta-\mathrm{NADPH}, \quad 250 \quad \mu \mathrm{mol} / 1$ tetrahydrobiopterin, $4 \mu \mathrm{mol} / \mathrm{l} \mathrm{FAD}, 4 \mu \mathrm{mol} / 1 \mathrm{FMN}$, $1 \mathrm{mmol} / 1 \mathrm{Ca}^{2+}, 1 \mathrm{mmol} / \mathrm{M} \mathrm{Mg}^{2+}$ in the total volume of $100 \mu 1$. After 20 -min incubation at $37^{\circ} \mathrm{C}$, the reaction was stopped by $1 \mathrm{ml}$ of ice-cold stop solution containing $20 \mathrm{mmol} / 1 \mathrm{HEPES}, \mathrm{pH} 5.5,2 \mathrm{mmol} / \mathrm{l}$ EDTA, $2 \mathrm{mmol} / 1$ EGTA and $1 \mathrm{mmol} / 1 \mathrm{~L}$-citrulline and applied to $50 \mathrm{WX}-8$
Dowex columns ( $\mathrm{Na}^{+}$form). $\left[{ }^{3} \mathrm{H}\right]$-L-citrulline was eluted by $1 \mathrm{ml}$ of distilled water and determined by liquid scintillation counting (Perkin Elmer Liquid Scintillation Analyzer, TriCarb 2910TR).

\section{Statistical analysis}

Data are presented as group mean values \pm SEM of the number (n) of observations. Results were analyzed by analysis of variance (ANOVA). One-way ANOVA was used to compare basic biometric and cardiovascular parameters, basal tension and inner diameter, vascular constrictions, nitric oxide synthase activity, $\mathrm{CD}$ and TBARS concentrations. In case of significant results pairwaise comparison with Bonferroni adjustment was employed. Concentration response curves were compared using two-way ANOVA, followed by vertical contrast with Bonferroni adjustment. Homogeneity of variances and normality of distribution were tested by Levene's test and by Shapiro-Wilk's test, respectively. To assess depression present at high concentration of AChcumulative concentration response curves, the maximal response and the response at higher ACh concentration at a particular response curve was compared with Dunnet's test (see Fig. 2). Means were considered to differ significantly when $\mathrm{p}<0.05$.

\section{Results}

Basic biometric and cardiovascular parameters, NO production and oxidative stress markers

Systolic blood pressure, heart rate, body mass, water intake and LVM/BM ratio of WKY, BHR and SHR rats are shown in Table 1. Normalized inner diameter was decreased by $10 \%$ in SHR and increased by $5 \%$ in BHR compared to WKY (Table 1). There was a significant positive correlation between normalized inner diameter at $13.3 \mathrm{kPa}$ and $\mathrm{BM}(\mathrm{r}=0.58, \mathrm{p}=0.006, \mathrm{n}=21)$. However, there were no significant differences in the resting FA wall tension of borderline hypertensive and hypertensive rats vs. WKY rats (Table 1). There were also no significant differences in the FA segment length after mounting among the groups (Table 1).

The NOS activity in the aorta was enhanced by $81 \%$ in BHR and by $106 \%$ in SHR vs. WKY $(\mathrm{p}<0.01$; Fig. 1). In the left ventricle, NOS activity was increased only in SHR, as compared to both BHR and WKY $(\mathrm{p}<0.01$; Fig. 1). Additionally, there were significant increases in TBARS and CD concentrations in the left ventricle of BHR and SHR (Table 1). 
Table 1. Basic biometric and cardiovascular parameters, oxidative stress markers, basal tension and inner diameter of adult WistarKyoto (WKY), borderline hypertensive (BHR) and spontaneously hypertensive (SHR) rats.

\begin{tabular}{|c|c|c|c|}
\hline & WKY & BHR & SHR \\
\hline Water intake (ml/100 g/day) & $8.1 \pm 0.2$ & $8.9 \pm 0.2^{* *}$ & $9.9 \pm 0.2 * *^{++}$ \\
\hline$B M(g)$ & $425.7 \pm 9.9$ & $481.7 \pm 5.9^{* *}$ & $385.3 \pm 10.1^{* *++}$ \\
\hline$B P(m m ~ H g)$ & $106 \pm 2$ & $143 \pm 3 * *$ & $191 \pm 3^{* *++}$ \\
\hline$H R(b p m)$ & $385 \pm 18$ & $405 \pm 13$ & $545 \pm 14^{* *+}$ \\
\hline$L V M / B M(\mathrm{mg} / \mathrm{g})$ & $1.45 \pm 0.02$ & $1.63 \pm 0.05^{*}$ & $2.18 \pm 0.05^{* *^{++}}$ \\
\hline TBARS-LV $(\mathrm{nmol} / \mathrm{g})$ & $8.25 \pm 0.48$ & $13.99 \pm 1.64 * *$ & $15.55 \pm 0.75^{* *}$ \\
\hline$C D-L V(n m o l / g)$ & $1054 \pm 26$ & $1238 \pm 78 * *$ & $1813 \pm 40^{* *^{++}}$ \\
\hline FA length $(\mathrm{mm})$ & $1.33 \pm 0.06$ & $1.32 \pm 0.07$ & $1.36 \pm 0.08$ \\
\hline$N D(\mu m)$ & $769 \pm 12$ & $806 \pm 11 *$ & $690 \pm 13^{* *++}$ \\
\hline$W T(\mathrm{mN} / \mathrm{mm})$ & $0.91 \pm 0.07$ & $0.92 \pm 0.05$ & $0.76 \pm 0.06$ \\
\hline
\end{tabular}

Values represent mean \pm SEM of 7-10 rats. BM - body mass, BP - blood pressure, CD - conjugated dienes, FA - femoral artery, HR heart rate, LV - left heart ventricle, LVM/BM - left ventricular mass-to-body mass, ND - normalized inner diameter of the femoral artery at $100 \mathrm{~mm} \mathrm{Hg}$, TBARS - thiobarbituric acid-reactive substances, WT- resting wall tension of the femoral artery. $* * p<0.01, * p<0.05$, compared to WKY rats; ${ }^{++} \mathrm{p}<0.01,{ }^{+} \mathrm{p}<0.05$, compared to BHR rats

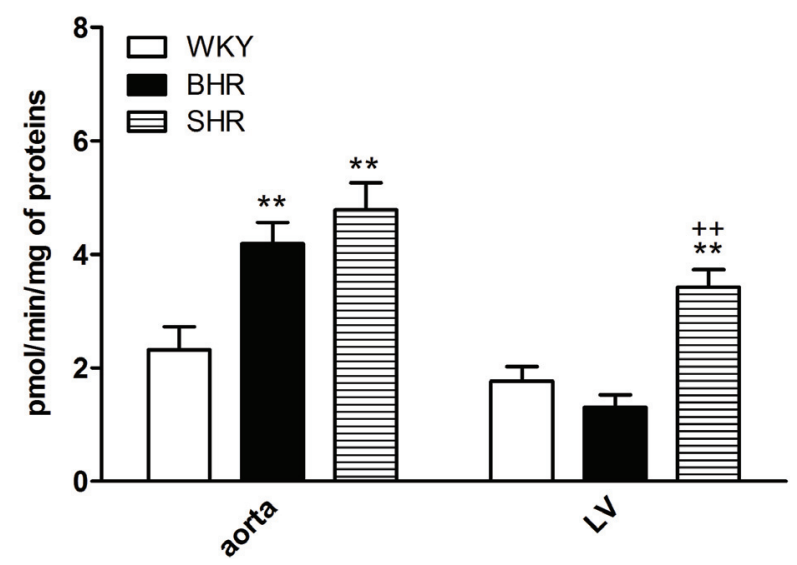

Fig. 1. Nitric oxide synthase activity of adult Wistar-Kyoto (WKY), borderline hypertensive (BHR) and spontaneously hypertensive $(\mathrm{SHR})$ rats. LV - left heart ventricle. Values represent mean $\pm \mathrm{SEM}$ of $6-8$ rats. ${ }^{* *} \mathrm{p}<0.01$, compared to WKY rats; ${ }^{++} \mathrm{p}<0.01$, compared to BHR rats

\section{Vascular responsiveness to vasoconstrictors}

Both noradrenaline $(10 \mu \mathrm{mol} / \mathrm{l})$ and serotonin ( $1 \mu \mathrm{mol} / \mathrm{l})$ induced contractile responses in the femoral arteries with intact endothelium; the maximum contractions are shown in Table 2. NA-induced responses were biphasic: a transient contraction (early response, phasic contraction), which occurred within the first 10$15 \mathrm{~s}$ and returned nearly to baseline was followed by sustained contraction (delayed response, tonic contraction), which reached steady maximum levels at 5 to $20 \mathrm{~min}$ (Fig. 2D). Maximum phasic and tonic contraction induced by NA was significantly greater in SHR than in WKY, but unchanged in BHR vs. WKY
(Table 2). However, only tonic contraction induced by NA determined in relative values (calculated as percentage of maximal response induced by KPSS) was significantly greater in SHR than in WKY (Table 2).

In the arteries pre-treated with the NOS inhibitor, the response to serotonin was augmented as compared to responses before L-NAME administration (Table 2). There were no significant changes in serotonin responses after L-NAME administration in BHR and SHR rats as compared to WKY rats. However, the difference between serotonin-induced contraction after and before L-NAME (to reveal basal, non-stimulated NO synthesis) was significantly increased in BHR rats compared to WKY and SHR, but comparable between the WKY and SHR groups (Table 2).

The absolute values for the maximum responses to KPSS were similar among the groups (Table 2).

Endothelium-dependent and-independent vasorelaxation

ACh ( $1 \mathrm{nmol} / \mathrm{l}-10 \mu \mathrm{mol} / \mathrm{l})$ and SNP ( $1 \mathrm{nmol} / \mathrm{l}$ $10 \mu \mathrm{mol} / \mathrm{l})$ relaxed the femoral artery in a concentrationdependent manner (Figs 2, 3A, 3C, 4A, 4C). Since serotonin $(1 \mu \mathrm{mol} / \mathrm{l})$ induced a reduced response in SHR vessels, resulting in a smaller pre-relaxation active tension level as compared to WKY (Table 2), the results were quantitatively expressed as $\mathrm{mN} / \mathrm{mm}$. ACh in serotonin-contracted femoral arteries could not induce a sustained relaxation and femoral arteries started to constrict again after a transient relaxation response (Fig. 2). WKY vessels relaxed significantly more in 
Table 2. Vascular constrictions induced by noradrenaline, high-potassium solution, pre-relaxation active tension responses induced by serotonin and maximal vasorelaxations based on the individual concentration-response curves of the femoral artery of Wistar-Kyoto (WKY), borderline hypertensive (BHR) and spontaneously hypertensive (SHR) rats.

\begin{tabular}{lccc}
\hline & \multicolumn{3}{c}{ Vasoconstriction (mN/mm) } \\
\cline { 2 - 4 } & WKY & BHR & SHR \\
\hline NA - phasic & $1.07 \pm 0.17$ & $1.39 \pm 0.16$ & $1.68 \pm 0.29^{*}$ \\
NA - tonic & $1.13 \pm 0.19$ & $1.20 \pm 0.22$ & $2.30 \pm 0.22^{* *++}$ \\
Ser before L-NAME & $7.41 \pm 0.15$ & $7.07 \pm 0.42$ & $6.05 \pm 0.50^{*}$ \\
Ser after L-NAME & $8.94 \pm 0.31^{\mathrm{xx}}$ & $9.90 \pm 0.40^{\mathrm{xx}}$ & $7.80 \pm 0.47^{++\mathrm{xx}}$ \\
Ser after and before L- & $1.53 \pm 0.30$ & $2.83 \pm 0.42^{*}$ & $1.76 \pm 0.22^{+}$ \\
NAME & $9.17 \pm 0.90$ & $8.99 \pm 0.58$ & $9.78 \pm 0.48$ \\
KPSS & & &
\end{tabular}

\begin{tabular}{lccc}
\hline & \multicolumn{3}{c}{ Relative vasoconstriction (\%) } \\
\cline { 2 - 4 } & WKY & BHR & SHR \\
\hline NA - phasic & $11.72 \pm 1.76$ & $15.60 \pm 1.59$ & $16.79 \pm 2.36$ \\
$N A-$ tonic & $13.46 \pm 3.19$ & $11.41 \pm 1.34$ & $23.35 \pm 1.68^{* *++}$ \\
Ser before $L-N A M E$ & $85.57 \pm 8.41$ & $77.04 \pm 6.65$ & $62.09 \pm 4.69^{*}$ \\
Ser after L-NAME & $102.04 \pm 8.13$ & $112.76 \pm 7.28^{\mathrm{xx}}$ & $79.82 \pm 3.15^{*+\times x}$ \\
\hline & & Baximal vasorelaxation (mN/mm) & SHR \\
\cline { 2 - 4 } & WKY & $3.96 \pm 0.12^{* *}$ & $2.83 \pm 0.19^{* *++}$ \\
\hline ACh before $L-N A M E$ & $4.80 \pm 0.15$ & $3.68 \pm 0.28$ & $1.99 \pm 0.40^{* *++x x}$
\end{tabular}

Values represent mean \pm SEM of 7-10 rats. $\Delta$ - difference, ACh - acetylcholine, KPSS - high-potassium physiological salt solution (identical with PSS, except with $\mathrm{NaCl}$ replaced by $\mathrm{KCl}$ on an equimolar basis), NA - noradrenaline (10 $\mu \mathrm{mol} / \mathrm{l})$, L-NAME - pre-treatment with $\mathrm{N}^{G}$-nitro-L-arginine methyl ester $(300 \mu \mathrm{mol} / \mathrm{l}, 25 \mathrm{~min})$, Ser - serotonin $(1 \mu \mathrm{mol} / \mathrm{l}) . * * \mathrm{p}<0.01, * \mathrm{p}<0.05$, compared to WKY rats; ${ }^{++} p<0.01,{ }^{+} p<0.05$, compared to BHR rats; ${ }^{x \times} p<0.01,{ }^{x} p<0.05$, compared to the respective value without L-NAME. Receptorindependent, maximum contraction response to KPSS $\left(125 \mathrm{mmol} / \mathrm{l} \mathrm{K}^{+}\right)$is expressed as $100 \%$ for calculation of the relative vasoconstrictions.

response to high, yet not to low acetylcholine concentrations than did BHR and SHR vessels (Figs 3A, 4A). In BHR and SHR, relaxing responses produced by $\mathrm{ACh}$ at concentrations greater than $0.3 \mu \mathrm{mol} / 1$ were smaller than maximal relaxations of the given genotype (Figs 2, 3A, 3B, 4A, 4B). Results revealed a greater endothelial dysfunction in SHR as compared to BHR (Figs 3A, 4A). However, there were small but significant differences in the relative values of $\mathrm{ACh}$-induced relaxations between BHR and SHR (Fig. 4A). Maximal absolute relaxations induced by $\mathrm{ACh}$, determined from the individual concentration-response curves, are shown in the Table 2. Relative maximal relaxations induced by $\mathrm{ACh}$ (based on the individual concentration-response curves) were significantly smaller in SHR $(58.47 \pm 2.52 \%, \quad \mathrm{p}<0.01)$ and BHR $\quad(60.88 \pm 2.75 \%$, $\mathrm{p}<0.05)$ than in WKY $(68.88 \pm 1.68 \%)$. Inhibition of nitric oxide synthesis with L-NAME in WKY and BHR had no effect on the maximal vasorelaxation, however it reduced significantly in SHR (Table 2). When the arteries were pre-treated with L-NAME, the femoral arteries from $\mathrm{BHR}$ and SHR rats responded by smaller relaxation to ACh than did the normotensive WKY arteries (Figs 3B, 4B). The NO-dependent component of ACh-induced relaxation, calculated as area under the individual curves, had increasing tendency in WKY, BHR and SHR (4.15 \pm 1.53 a.u., $4.80 \pm 1.23$ a.u., $5.18 \pm 1.04$ a.u. calculated from absolute relaxations and $102 \pm 17$ a.u., $118 \pm 17$ a.u., $146 \pm 16$ a.u. calculated from relative relaxations, respectively, n.s.) rats. However, significant positive correlation was found between systolic BP and NOdependent vasorelaxation (Fig. 6B). The NO-dependent 

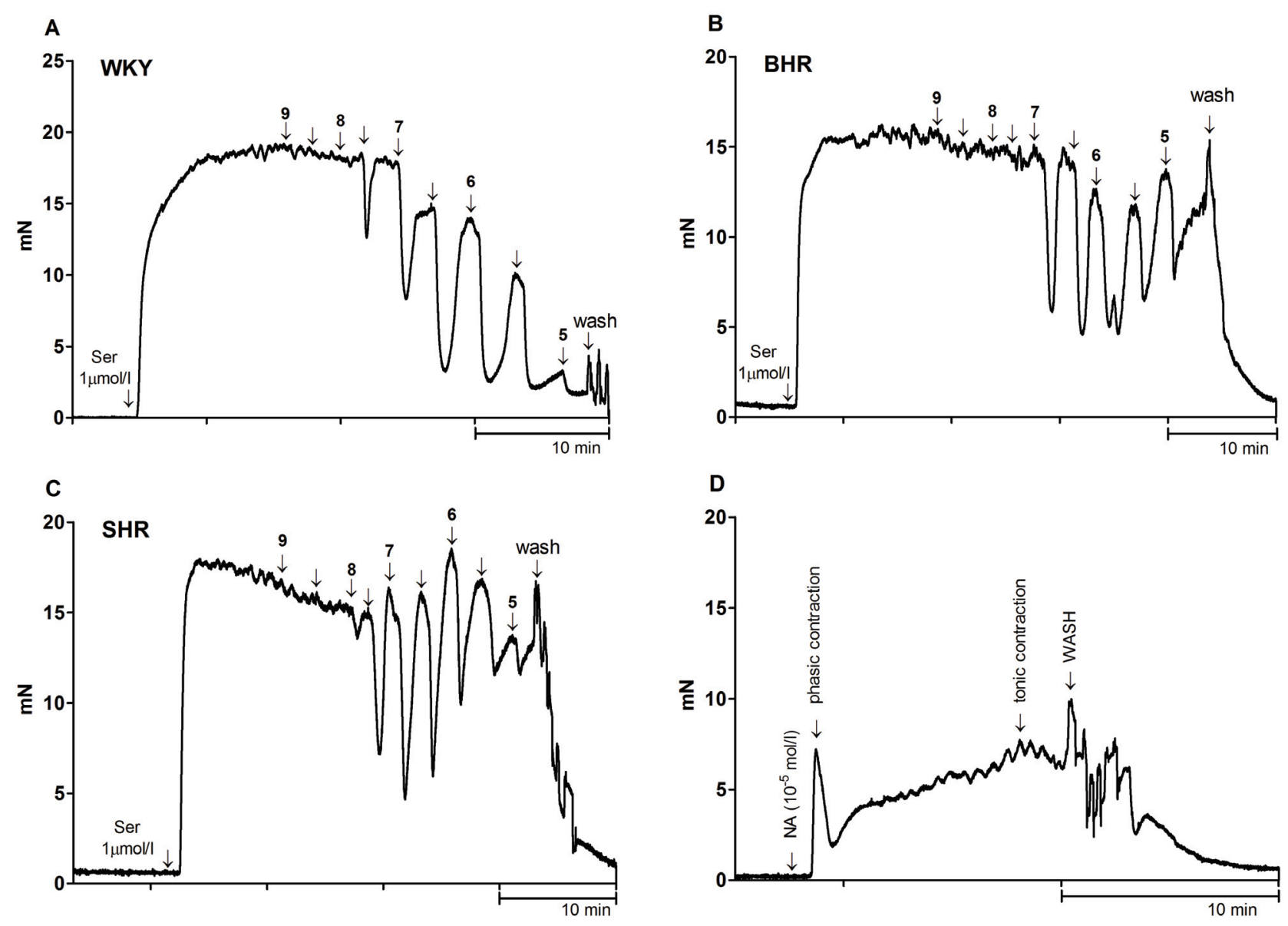

Fig. 2. Representative traces showing the typical relaxation response of serotonin (Ser) pre-contracted femoral artery on acetylcholine (ACh, $1 \mathrm{nmol} / \mathrm{I}-10 \mu \mathrm{mol} / \mathrm{I})$ in Wistar-Kyoto (WKY, A), borderline hypertensive (BHR, B) and spontaneously hypertensive (SHR, C) rats. Rings were exposed to increasing concentrations of $\mathrm{ACh}$ in -log mol/l units (see charts). The time axis intervals represent 10 minutes. Charts of BHR and SHR femoral artery depicting impaired relaxation responses at higher ACh concentrations as compared to maximal relaxation at lower-concentrations of $\mathrm{ACh}$, indicating release of counterbalancing vasocontractile factors in hypertensive animals. D shows the typical contraction response to noradrenaline (NA, $10 \mu \mathrm{mol} / \mathrm{l})$ in WKY rats.

relaxation calculated as the difference between total relaxation (Figs 3A and 4A) and L-NAME-resistant relaxation (Figs 3B and 4B) are shown in Fig. 5A and Fig. 5B. The NO-independent component of AChinduced relaxation was decreased in BHR $(12.61 \pm 1.47$ a.u. as compared to $17.49 \pm 1.83$ a.u. in WKY, $\mathrm{p}<0.05$ ) and SHR (7.32 \pm 1.68 a.u. as compared to WKY and BHR, $\mathrm{p}<0.05$ ). There was also a significant negative correlation between $\mathrm{BP}$ and absolute NO-independent vasorelaxation $(\mathrm{r}=-0.656, \mathrm{p}=0.0004, \mathrm{n}=25)$. Moreover, significant negative correlations were found between systolic BP and relative NO-independent vasorelaxation (Fig. 6A).

Cumulative addition of NO donor sodium nitroprusside (SNP) produced similar relaxation responses in the femoral artery from BHR, SHR and WKY rats (Figs 3C, 4C).

\section{Discussion}

The presented study was designed to reveal the severity of vascular alterations in adult borderline hypertensive rats as compared to normotensive and hypertensive rats. Special attention was paid to the NOdependent and independent components of vasorelaxation. The study revealed attenuated acetylcholine-induced relaxation in the serotonin pre-contracted FA of both adult BHR and SHR, which was associated with reduction of the NO-independent component of relaxation. Additionally, there were significant between-strain related alterations in mechanism of relaxation resulting in negative correlation between $\mathrm{BP}$ and NO-independent component and positive correlation between BP and NO-dependent component of vasorelaxation. Moreover, biochemical analysis showed elevated NO production as well as oxidative stress in rats with increased BP. 
A

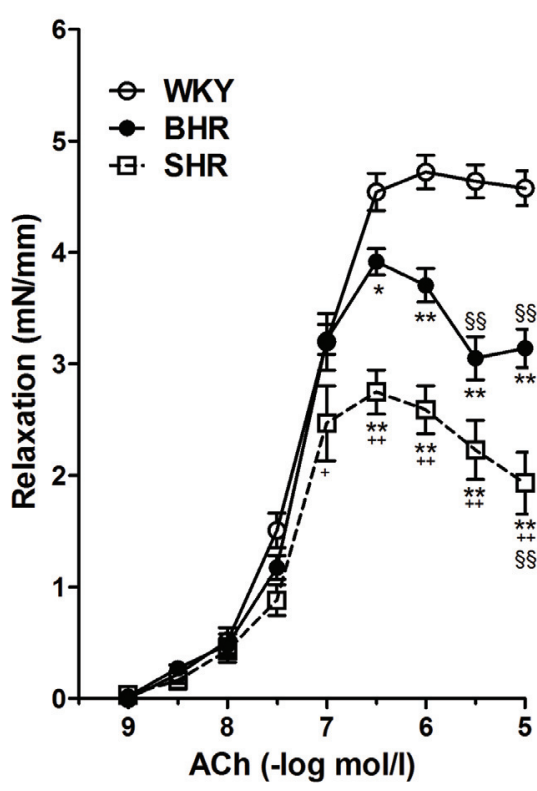

B

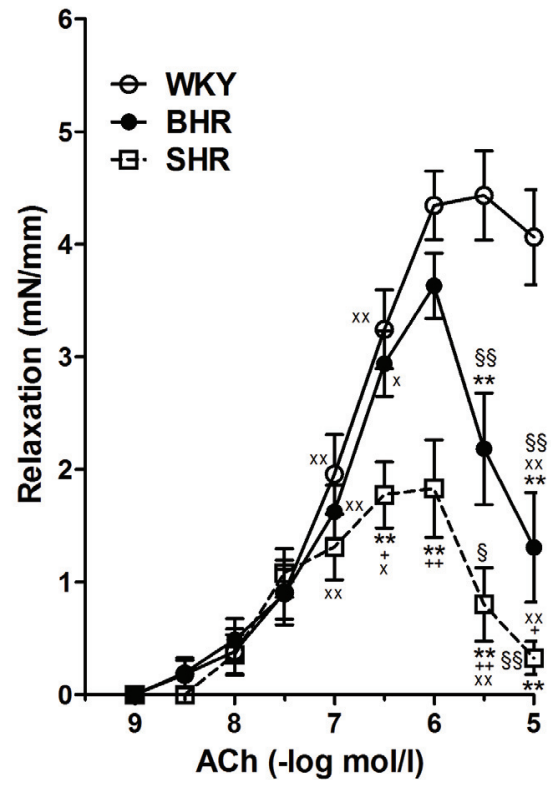

C

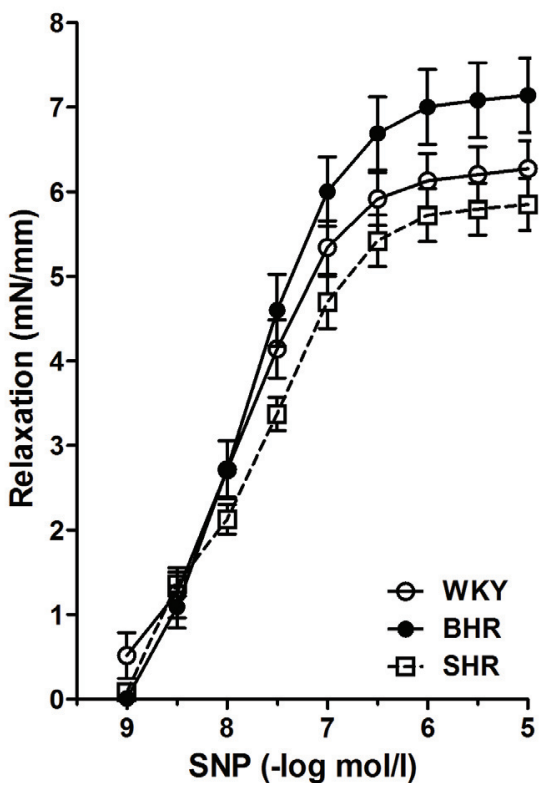

Fig. 3. Vascular responses (absolute changes) to acetylcholine (ACh) in isolated femoral arteries of Wistar-Kyoto (WKY), borderline hypertensive (BHR) and spontaneously hypertensive (SHR) rats. In serotonin-contracted rings with endothelium of WKY, BHR and SHR, ACh causes relaxations which at higher concentrations are blunted in the arteries of the hypertensive strain. Endothelium-dependent relaxations before $(\mathbf{A})$ and after $(\mathbf{B})$ incubation with the nitric oxide (NO) synthase inhibitor $\mathrm{N}^{\mathrm{G}}$-nitro-L-arginine methyl ester (L-NAME, i.e. NO-independent component of ACh-induced relaxation); Sodium nitroprusside (SNP)-induced endothelium-independent relaxation (C). Values represent mean \pm SEM of 7-10 rats. $* * p<0.01, * p<0.05$, compared to respective value in WKY rats; ${ }^{++} p<0.01,{ }^{+} p<0.05$, compared to respective value in BHR rats; ${ }^{x x} p<0.01,{ }^{x} p<0.05$, compared to respective value without L-NAME; ${ }^{\S \S} p<0.01,{ }^{\S} p<0.05$, compared to maximal relaxation at ACh concentrations $0.3 \mu \mathrm{mol} / \mathrm{l}(\mathrm{A})$ and $1 \mu \mathrm{mol} / \mathrm{l}(B)$

A

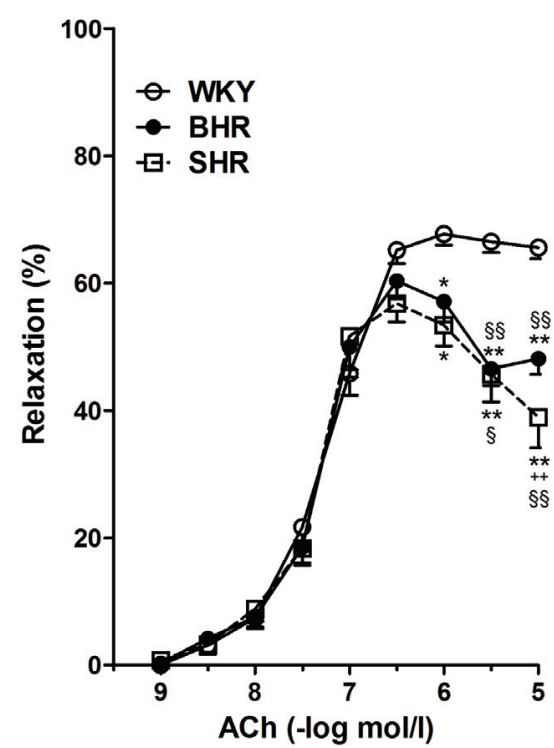

B

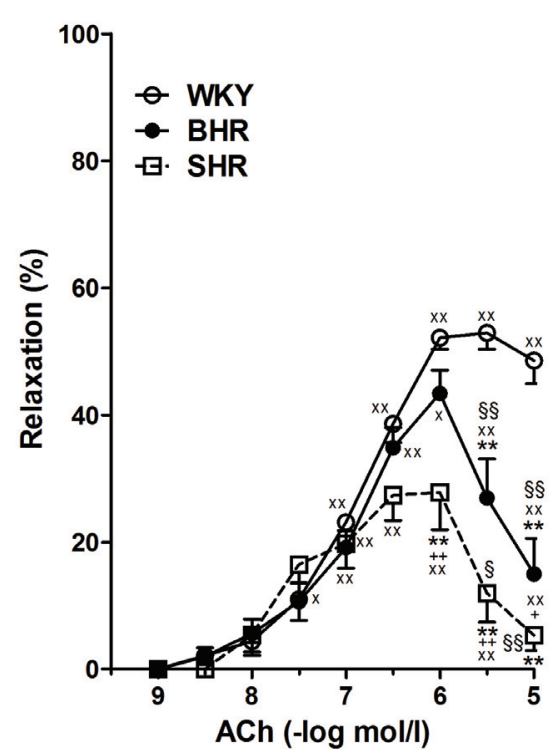

C

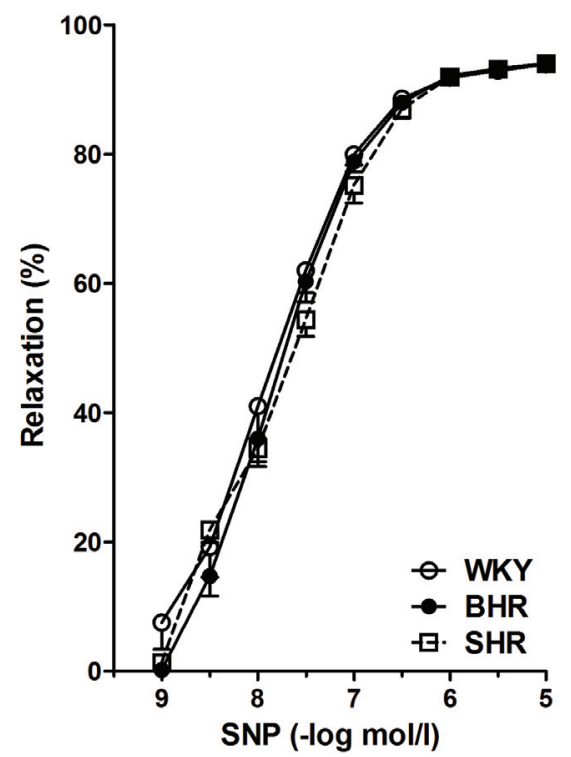

Fig. 4. Vascular responses (relative changes) to acetylcholine (ACh) in the isolated femoral arteries of Wistar-Kyoto (WKY), borderline hypertensive (BHR) and spontaneously hypertensive (SHR) rats. Relaxation responses were expressed as the percentage of relaxation respect to the pre-contraction induced by serotonin $(1 \mu \mathrm{mol} / \mathrm{l})$. The pre-contraction plateau value reached after serotonin administration corresponds to $100 \%$. In serotonin-contracted rings with endothelium of WKY, BHR and SHR, ACh causes relaxations which at higher concentrations are blunted in the arteries of the hypertensive strain. Endothelium-dependent relaxations before (A) and after (B) incubation with the nitric oxide (NO) synthase inhibitor $\mathbf{N}^{\mathrm{G}}$-nitro-L-arginine methyl ester (L-NAME, i.e. NO-independent component of ACh-induced relaxation); Sodium nitroprusside (SNP)-induced endothelium-independent relaxation (C). Values represent mean \pm SEM of 7-10 rats. ${ }^{* *} p<0.01, * p<0.05$, compared to respective value in WKY rats; ${ }^{++} p<0.01,{ }^{+} p<0.05$, compared to respective value in BHR rats; ${ }^{x x} p<0.01,{ }^{x} p<0.05$, compared to respective value without L-NAME; ${ }^{\S \S} p<0.01,{ }^{\S} p<0.05$, compared to maximal relaxation at $A C h$ concentrations $0.3 \mu \mathrm{mol} / \mathrm{l}(\mathrm{A})$ and $1 \mu \mathrm{mol} / \mathrm{l}(\mathrm{B})$ 
A

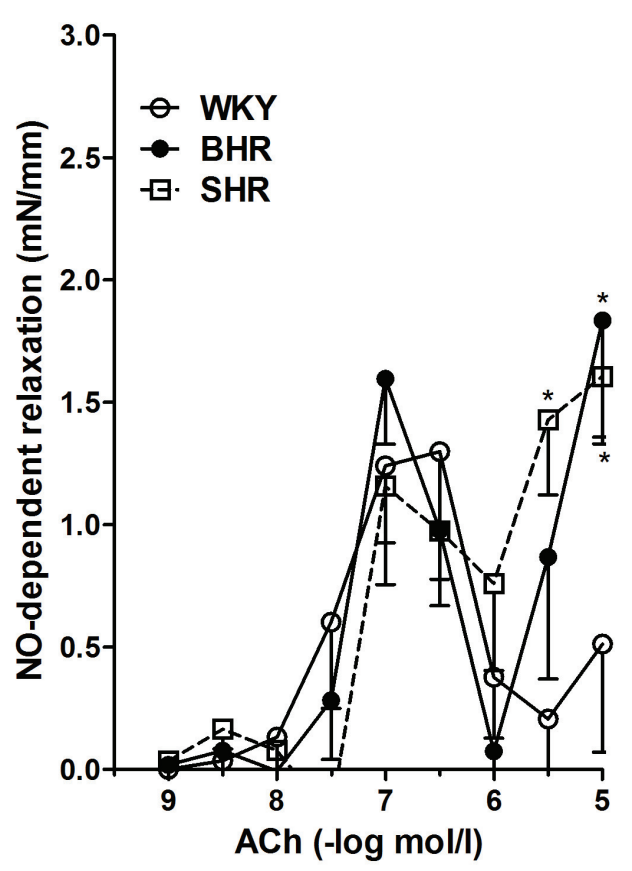

B

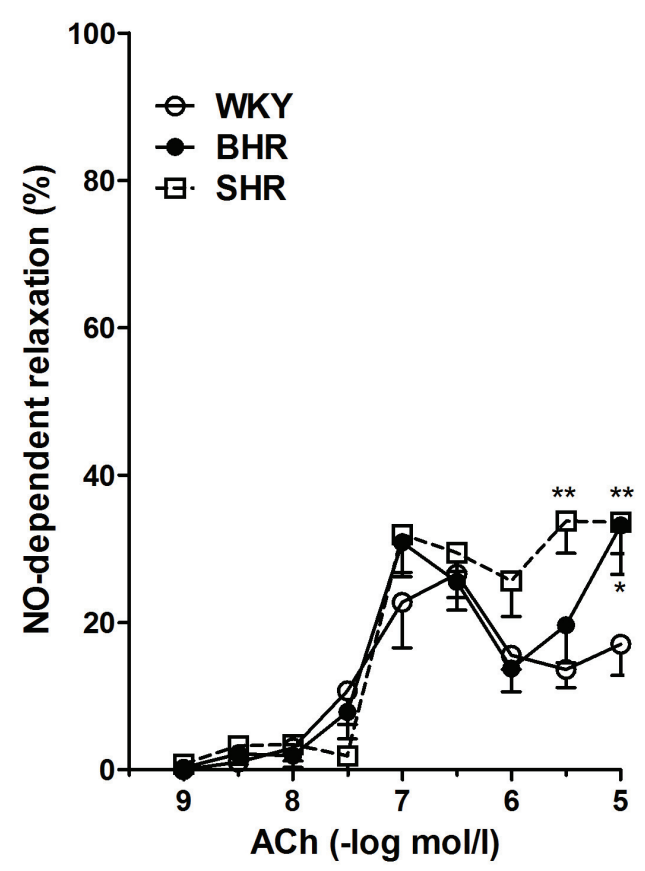

Fig. 5. Nitric oxide (NO)-dependent relaxations (relative and absolute changes) in the isolated femoral arteries of Wistar-Kyoto (WKY), borderline hypertensive (BHR) and spontaneously hypertensive (SHR) rats. Nitric oxide (NO)-dependent relaxation (in $\mathrm{mN} / \mathrm{mm}$ ) calculated as the difference between total acetylcholine (ACh)-induced relaxing curves (Fig. 3A) and L-NAME-resistant relaxation (Fig. 3B) (A). Nitric oxide (NO)-dependent relaxation (in percentage) calculated as the difference between total acetylcholine (ACh)induced relaxing curves (Fig. 4A) and L-NAME-resistant relaxation (Fig. 4B) (B). Relaxation responses are expressed as the percentage of relaxation to the pre-contraction induced by serotonin $(1 \mu \mathrm{mol} / \mathrm{l})$. Values represent mean $\pm \mathrm{SEM}$ of 7-10 rats. L-NAME $-\mathrm{N}^{\mathrm{G}}-\mathrm{nitro}-\mathrm{L}-$ arginine methyl ester; $* * p<0.01, * p<0.05$, compared to respective value in WKY rats

Elevated systolic blood pressure in both BHR and SHR was accompanied by an increase of relative left ventricle mass, indicating left ventricular hypertrophy. It is well known that left ventricular hypertrophy results from the interaction of systemic hemodynamic overload and local non-hemodynamic factors, and thus NO may play a significant role in its development. Indeed, in the model of NO-deficient hypertension, local reduction of NO production rather than hemodynamic overload were associated with the degree of LV hypertrophy (Bernátová et al. 1999). According to our current data, however, LV hypertrophy occurred without alterations in NO production in the LV of BHR and even in the presence of increased NOS activity in SHR. It is yet to be noted that the oxidative stress markers were increased in the LV of both BHR and SHR. Thus oxidative stress may contribute to the development of hypertrophy induced by multiple mechanisms including G-protein-coupled receptor agonists and mechanical stretch (Grieve et al. 2006) as well as reduction of NO bioavailability in the LV (Pechánová et al. 2007, 2009). Similarly, vascular wall remodeling is common feature in hypertension (Paulis et al. 2007, 2008). We observed reduced internal diameter in the FA in SHR and increased diameter in BHR without alterations in resting wall tension, which suggest no changes in the passive elements of the vascular wall (Koprdova et al. 2009). In fact we observed that internal diameter in the FA correlated positively with BM.

As mentioned above, despite enormous effort, the mechanisms underlying ED in hypertension are not satisfactorily understood and methodological aspects represent a significant limitation of our current knowledge. In contrast to our previous findings of unchanged $\mathrm{ACh}$-induced relaxation in the phenylephrine (Phe) pre-contracted FA of BHR and even improved relaxation in SHR vs. WKY rats (Púzserová et al. 2007) and vs. Wistar rats (Bernatova et al. 2007), our current study revealed ED in both BHR and SHR as compared to WKY. Since between-strain differences were detected in the magnitude of pre-contraction induced by serotonin, the role of differences in pre-relaxation tone cannot be rule out ( $\mathrm{Li}$ and Bukoski 1993). As Hansen and Nedergaard (1999) have previously demonstrated that the ACh-induced relaxation was inversely related to precontractile tension when expressed as a percentage, but independent when expressed in absolute values, 
A

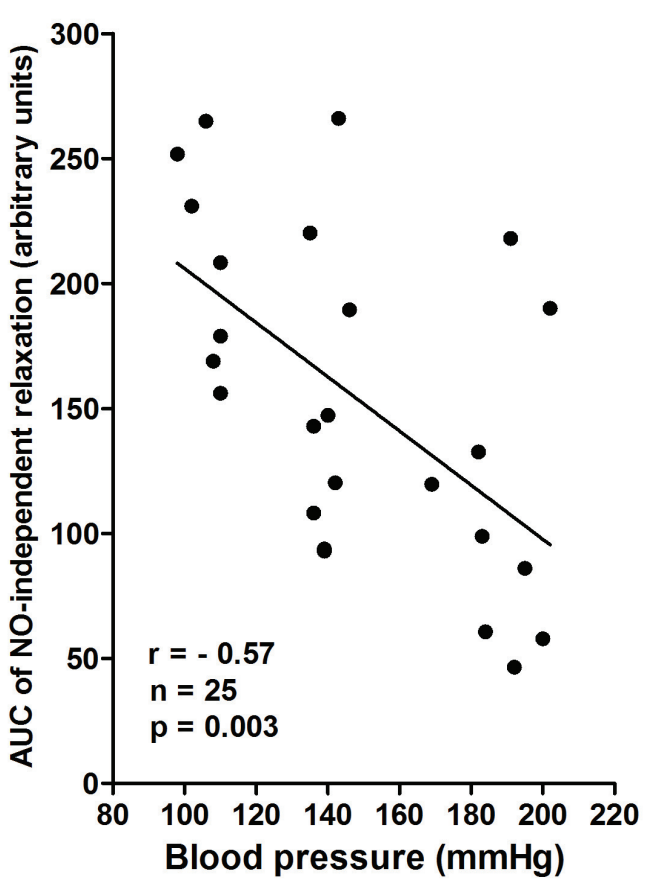

B

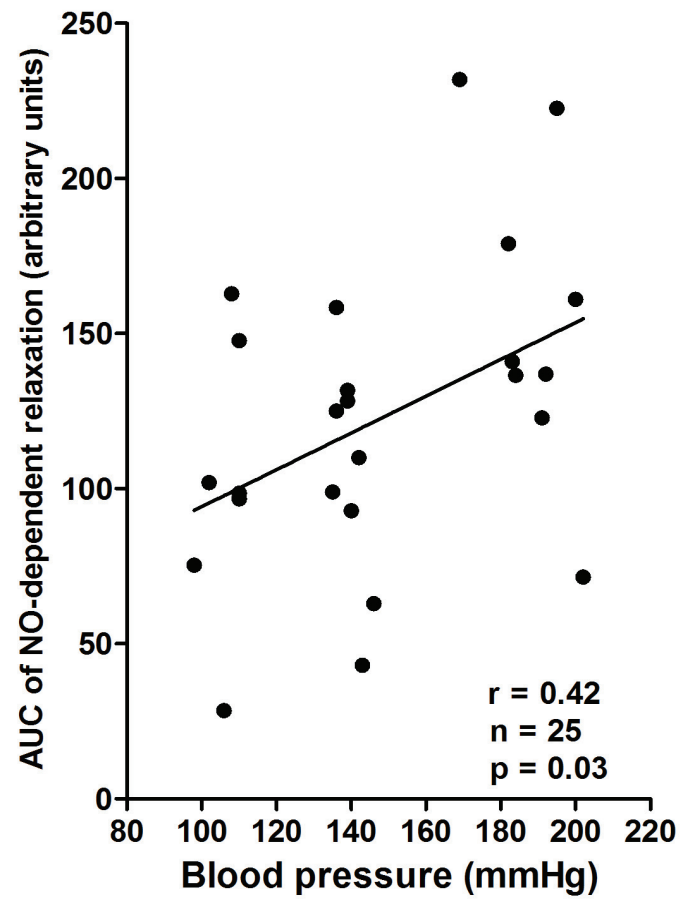

Fig. 6. Vascular responses (relative changes) to acetylcholine (ACh) in the isolated femoral arteries of Wistar-Kyoto (WKY), borderline hypertensive (BHR) and spontaneously hypertensive (SHR) rats. Correlation between NO-independent component of vasorelaxation (calculated from relative relaxations) and blood pressure (A). Correlation between NO-dependent component of vasorelaxation (calculated from relative relaxations) and blood pressure (B). Values represent mean \pm SEM of 7-10 rats. AUC - area under the curve

vasorelaxations in this study were determined also in absolute values. The results calculated on the basis of absolute tension were similar to those obtained in percentages (Fig. 3, Fig. 4), however, determination of relaxation in absolute values revealed a more pronounced ED in SHR vs. BHR, which was not associated with NO deficiency. The present results also suggest that the responsiveness of vascular smooth muscles to NO was not impaired since relaxant responses to SNP were unchanged. Differences in our studies were presumably related to methodological aspects. Namely, relaxant responses to $\mathrm{ACh}$ were determined in serotonin (Fujimoto and Fujimoto 2001) pre-contracted arteries instead of phenylephrine (Bernatova et al. 2007, Púzserová et al. 2007) in order to avoid spontaneous relaxation, which can occur in the Phe pre-contracted FA. In this context, it has been reported that endotheliumdependent vasorelaxation of SHR resistance arteries is not impaired under any conditions and appears to be a function of the agonist used to pre-constrict the vessels (Li and Bukoski 1993).

Moreover, addition of antioxidants, e.g. ascorbic acid (AsA), to solution (to PSS or to solution for dilution of some drugs) used in vascular in vitro studies may also be of importance (Bernatova et al. 2009). In addition to above mentioned modifications, our previous observations of the absence of ED in BHR and SHR were achieved in the presence of AsA (Bernatova et al. 2007, Púzserová et al. 2007). Similarly to our studies, absence of ED was shown in the presence of AsA in various arteries of adult SHR (Török and Kristek 2001, Cacányiová and Kristek 2008, Lísková et al. 2010). However, AsA might artificially reverse ED by improvement of oxidative status resulting in better NO bioavailability (May 2000, Bernatova et al. 2009). On the other hand, preserved ACh-induced relaxation was reported also in the adult SHR aorta in absence of antioxidants (Lorkowska et al. 2006). Furthermore even greater relaxation responses were observed in the adult SHR FA compared to their normotensive counterparts (Konishi and Su 1983). On the contrary, a reduced AChinduced vasorelaxation was reported in the iliac artery in SHR in the presence of AsA (Cacányiová et al. 2006).

The investigation of vasorelaxation by cumulative addition of $\mathrm{ACh}$ revealed also considerable differences in the course of vascular responses of WKY, BHR and SHR, mainly at higher ACh concentrations. It is well known that higher concentrations of $\mathrm{ACh}$ may 
elicit production of endothelium-derived vasoconstrictive cyclooxygenase-generated prostaglandins in adult SHR arteries, simultaneously with EDRFs (Lüscher and Vanhoutte 1986, Jameson et al. 1993, Vanhoutte 2009). Previously reported EDCFs include endothelin, cyclooxygenase-derived prostanoids or free radicals $(\mathrm{Li}$ and Bukoski 1993, Paulis et al. 2008, Török 2008, Cacányiová and Kristek 2008, Vanhoutte et al. 2005, Vanhoutte 2009). The dysbalance between EDRFs and EDCFs was shown to be progressively increasing not only with advancing age, but also by hypertension development (Lišková et al. 2011). Similarly, in this study the EDCFs release was present only in hypertensive animals as determined by stronger depression of relaxation curves at higher concentration (more than $1 \mu \mathrm{mol} / 1$ in this study) of acetylcholine compared to normotensive animals. Moreover, the release of EDCFs was not observed in age-matched WKY rats, similarly as it was found previously (Líšková et al. 2011). In contrast, the EDCFs-mediated contractions were not seen in the FA of BHR and SHR pre-contracted with phenylephrine in the presence of AsA (Púzserová et al. 2007), which is in agreement with the idea that reactive oxygen species, namely superoxide anion, accelerate endotheliumdependent contractions to ACh in SHR (Jameson et al. 1993, Vanhoutte et al. 2005, Vanhoutte 2009). Furthermore, the EDCFs-mediated contractile responses in the FA of BHR and SHR were augmented after preincubation with L-NAME, suggesting that NO counterbalances the effect of EDCFs.

An interesting result of this study was the observation of reduced NO-independent (i.e. L-NAMEresistant) component of ACh-induced relaxation. It is an important finding as many studies investigating vascular function by ACh test assume that NO deficiency is the major factor of endothelial dysfunction. As the $\mathrm{N}^{\mathrm{G}}$-nitroL-arginine (an inhibitor of NOS) in the combination with tetraethylammonium or charybdotoxin (inhibitors of EDHFs-mediated responses) and indomethacin (cyclooxygenase inhibitor) completely abolished the relaxant response to $\mathrm{ACh}$ in the adult SHR femoral artery (Fujimoto and Fujimoto 2001) we assume that the NOindependent component is related to endothelium-derived hyperpolarizing factors and $\mathrm{PGI}_{2}$ dependent vasorelaxation in this artery. This study showed that ED (at least in the femoral artery) observed in experimental model of genetic prehypertension and hypertension was related rather to the decreased EDHFs-mediated and/or $\mathrm{PGI}_{2}$-mediated vasorelaxation (Li et al. 1994, Kähönen et al. 1995, Fujimoto and Fujimoto 2001, Mori et al. 2006) than to lack of NO. Indeed, there was positive correlation between NO-dependent component of relaxation and BP, similarly as we observed previously (Púzserová et al. 2007).

Also of interest is our observation that maximal ACh-induced relaxation of SHR vessels was inhibited by L-NAME, whereas this blocker was without effect on maximal relaxations of WKY and BHR vessels. Similar observations were reported by $\mathrm{Li}$ and Bukoski (1993). This observation suggests that compensatory EDHFs production may occur in normotensive rats after acute NOS inhibition (Bauersachs et al. 1996) while this mechanism is impaired in SHR rats (Púzserová et al. 2010).

Regarding vasoconstriction, this study demonstrated that phasic and tonic contractile responses to noradrenaline were larger in SHR than in WKY. Similar findings were observed by Asano et al. (1982) in the FA of adult female SHR, which was associated with the decrease in $\beta$-adrenoceptor relaxing responses and accompanied by an enhanced vasoconstriction induced by NA. Reduced $\beta$-adrenoceptor-mediated relaxation was found in the femoral artery in adult SHR males (Konishi and Su 1983) as well as in young SHR males in the prehypertensive period (Fujimoto et al. 1987). Thus it is likely that a decrease in $\beta$-adrenoceptor activity would result in potentiation of vasoconstriction by unopposed $\alpha$ adrenoceptor stimulation (Asano et al. 1982). Our results also suggest differences in sensitivity and/or distribution of alpha and beta adrenoceptors between adult BHR and SHR since NA-induced tonic vasoconstriction of BHR was similar to that in WKY and significantly lower compared to SHR. Additionally, Líšková et al. (2011) suggested the enhanced contribution of EDCFs in NAinduced contraction of the femoral arteries in adult SHR.

Biochemical findings support the idea that the Larginine/NO system may serve as a compensatory mechanism activated in response to increased blood pressure in SHR, because NO is known to counterbalance the effect of sympathetic stimulation on the peripheral as well as central level (Török 2008). Indeed, several studies, including ours, observed elevated NO production in SHR (Chen and Hu 1997, Radaelli et al. 1998, Vaziri et al. 2000, Zalba et al. 2001, Hojná et al. 2007, Pechánová et al. 2007, 2009, Púzserová et al. 2007, Török 2008). Considering the presence of oxidative stress, elevated NO production may be a consequence of free radical-induced activation of $\mathrm{NF}-\kappa \mathrm{B}$, transcriptional 
factor for NOS (Kopincová et al. 2011). On the other hand, oxidative load may also reduce NO bioavailability (Pechánová et al. 2007), so that NO may be unable to induce greater NO-dependent vasodilatation, despite increased vascular NO synthesis. Moreover, even though NO-dependent vasorelaxation was not reduced in hypertensive rats, we cannot exclude relative NO deficiency as compared to the existing sympathetic overactivity (Kunes et al. 2004, Paulis et al. 2007, Török 2008, Behuliak et al. 2011) as suggested by increased drinking volume (Kraly et al. 1985) and elevated HR in SHR as compared to both WKY and BHR.

The observations of elevated CD and TBARS support the idea that oxidative stress may be a factor contributing to LV hypertrophy as well as ED in genetic hypertension. However, persistent elevation of NO and superoxide levels can result in generation of peroxynitrite, a potent oxidant and tissue-damaging agent, resulting in impairment of cellular signaling (Durackova 2010, Kopincová et al. 2011). It is thus not clear whether NO would remain a protective compensatory molecule over a prolonged time-course of hypertension. Taking into account all aforementioned results, the reduced endothelium-dependent relaxations to $\mathrm{ACh}$ in the femoral arteries of BHR and SHR were not due to a decreased release of NO but rather to other EDRFs and/or to the simultaneous release of EDCFs.

In conclusion, this study showed that LV hypertrophy and ED were present in both adult BHR and SHR. Moreover, the results revealed that the degree of
ED was associated with the level of BP. LV hypertrophy and ED observed in this study did not result from reduced NO synthesis. The most important finding of this study was that the NO-independent component of endotheliumdependent ACh-induced relaxation in serotonin precontracted FA correlated negatively with BP. Thus, the results suggest that both in BHR and SHR rats, ED was not associated with reduced NO production. Additionally, the results indicate that borderline hypertension in adulthood represents qualitatively a similar risk of other cardiovascular diseases as does fully developed hypertension. Therefore it is important to study vascular mechanisms in conditions of moderately increased blood pressure in order to prevent pressure-induced organ damage, which can further accelerate the development of serious hypertension.

\section{Conflict of Interest}

There is no conflict of interest.

\section{Acknowledgements}

The authors thank to Mrs. Jana Petova for her technical assistance. This study was supported by the Slovak Grant Agency for Science, grant No. 2/0084/10, Slovak Research and Development Agency, grant No. APVV0523-10 and within the project of "ITMS 26240120006Establishment of the Centre for the Research on Composite Materials for Structural, Engineering and Medical Applications-CEKOMAT I".

\section{References}

ASANO M, AOKI K, MATSUDA T: Reduced beta adrenoceptor interactions of norepinephrine enhance contraction in the femoral artery from spontaneously hypertensive rats. J Pharmacol Exp Ther 223: 207-214, 1982.

BAUERSACHS J, POPP R, HECKER M, SAUER E, FLEMING I, BUSSE R: Nitric oxide attenuates the release of endothelium-derived hyperpolarizing factor. Circulation 94: 3341-3347, 1996.

BEHULIAK M, PINTÉROVÁ M, KUNEŠ J, ZICHA J: Vasodilator efficiency of endogenous prostanoids, $\mathrm{Ca}^{2^{+}-}$ activated $\mathrm{K}^{+}$channels and nitric oxide in rats with spontaneous, salt-dependent or NO-deficient hypertension. Hypertens Res 34: 968-975, 2011.

BERNÁTOVÁ I, PECHÁNOVÁ O, KRISTEK F: Mechanism of structural remodelling of the rat aorta during longterm $\mathrm{N}^{\mathrm{G}}$-nitro-L-arginine methyl ester treatment. Jpn J Pharmacol 81: 99-106, 1999.

BERNATOVA I, CSIZMADIOVA Z, KOPINCOVA J, PUZSEROVA A: Vascular function and nitric oxide production in chronic social-stress-exposed rats with various family history of hypertension. $J$ Physiol Pharmacol 58: 487-501, 2007.

BERNATOVA I, CONDE MV, KOPINCOVA J, GONZALEZ MC, PUZSEROVA A, ARRIBAS SM: Endothelial dysfunction in spontaneously hypertensive rats: focus on methodological aspects. J Hypertens Suppl 27: S27S31, 2009. 
CACÁNYIOVÁ S, KRISTEK F: Adaptive vasoactive response to modulatory effects of endothelin-1 in spontaneously hypertensive rats. Pharmacol Rep 60: 941-949, 2008.

CACÁNYIOVÁ S, CEBOVÁ M, KUNES J, KRISTEK F: Comparison of vascular function and structure of iliac artery in spontaneously hypertensive and hereditary hypertriglyceridemic rats. Physiol Res 55 (Suppl 1): S73-S80, 2006.

CHEN HI, HU CT: Endogenous nitric oxide on arterial hemodynamics: a comparison between normotensive and hypertensive rats. Am J Physiol 273: H1816-H1823, 1997.

CHOBANIAN AV, BAKRIS GL, BLACK HR, CUSHMAN WC, GREEN LA, IZZO JL Jr, JONES DW, MATERSON BJ, OPARIL S, WRIGHT JT Jr, ROCCELLA EJ: The Seventh Report of the Joint National Committee on Prevention, Detection, Evaluation, and Treatment of High Blood Pressure: the JNC 7 report. JAMA 289: 25602572, 2003.

DURACKOVÁ Z: Some current insights into oxidative stress. Physiol Res 59: 459-469, 2010.

DURANTE P, CHÁVEZ M, PÉREZ M, ROMERO F, RIVERA F. Effect of uric acid on hypertension progression in spontaneously hypertensive rats. Life Sci 86: 957-964, 2010.

FUCHS LC, HOQUE AM, CLARKE NL: Vascular and hemodynamic effects of behavioral stress in borderline hypertensive and Wistar-Kyoto rats. Am J Physiol 274: R375-R382, 1998.

FUJIMOTO S, FUJIMOTO SK: Elcatonin-mediated contractile and relaxant responses in SHR femoral artery. Acta Pharmacol Sin 22: 595-602, 2001.

FUJIMOTO S, DOHI Y, AOKI K, ASANO M, MATSUDA T: Diminished beta-adrenoceptor-mediated relaxation of arteries from spontaneously hypertensive rats before and during development of hypertension. Eur $J$ Pharmacol 136: 179-187, 1987.

GRIEVE DJ, BYRNE JA, SIVA A, LAYLAND J, JOHAR S, CAVE AC, SHAH AM: Involvement of the nicotinamide adenosine dinucleotide phosphate oxidase isoform Nox2 in cardiac contractile dysfunction occurring in response to pressure overload. $J$ Am Coll Cardiol 47: 817-826, 2006.

GÜNDÜZ F, KOÇER G, ULKER S, MEISELMAN HJ, BAŞKURT OK, SENTÜRK UK: Exercise training enhances flow-mediated dilation in spontaneously hypertensive rats. Physiol Res 60: 589-597, 2011.

HANSEN K, NEDERGAARD OA: Methodologic aspects of acetylcholine-evoked relaxation of rabbit aorta. J Pharmacol Toxicol Methods 41: 153-159, 1999.

HOJNÁ S, KADLECOVÁ M, DOBESOVÁ Z, VALOUSKOVÁ V, ZICHA J, KUNES J: The participation of brain NO synthase in blood pressure control of adult spontaneously hypertensive rats. Mol Cell Biochem 297: 21-29, 2007.

HU ML, FRANKEL EN, LEIBOVITZ BE, TAPPEL AL: Effect of dietary lipids and vitamin E on in vitro lipid peroxidation in rat liver and kidney homogenates. $J$ Nutr 119: 1574-1582, 1989.

JAMESON M, DAI FX, LÜSCHER T, SKOPEC J, DIEDERICH A, DIEDERICH D: Endothelium-derived contracting factors in resistance arteries of young spontaneously hypertensive rats before development of overt hypertension. Hypertension 21: 280-288, 1993.

KÄHÖNEN M, MÄKYNEN H, WU X, ARVOLA P, PÖRSTI I: Endothelial function in spontaneously hypertensive rats: influence of quinapril treatment. Br J Pharmacol 115: 859-867, 1995.

KONISHI M, SU C: Role of endothelium in dilator responses of spontaneously hypertensive rat arteries. Hypertension 5: 881-886, 1983.

KOPINCOVÁ J, PÚZSEROVÁ A, BERNÁTOVÁ I: Biochemical aspects of nitric oxide synthase feedback regulation by nitric oxide. Interdiscip Toxicol 4: 63-68, 2011.

KOPRDOVA R, CEBOVA M, KRISTEK F: Long-term effect of losartan administration on blood pressure, heart and structure of coronary artery of young spontaneously hypertensive rats. Physiol Res 58: 327-335, 2009.

KRALY FS, COOGAN LA, SPECHT SM, TRATTNER MS, ZAYFERT C, COHEN A, GOLDSTEIN JA: Disordered drinking in developing spontaneously hypertensive rats. Am J Physiol 248: R464-R470, 1985.

KUNES J, HOJNÁ S, KADLECOVÁ M, DOBESOVÁ Z, RAUCHOVÁ H, VOKURKOVÁ M, LOUKOTOVÁ J, PECHÁNOVÁ O, ZICHA J: Altered balance of vasoactive systems in experimental hypertension: the role of relative NO deficiency. Physiol Res 53 (Suppl 1): S23-S34, 2004. 
KUNEŠ J, KADLECOVÁ M, VANĚČKOVÁ I, ZICHA J: Critical developmental periods in the pathogenesis of hypertension. Physiol Res 61 (Suppl 1): S9-S17, 2012.

LAWLER JE, BARKER GF, HUBBARD JW, SCHAUB RG: Pathophysiological changes associated with stressinduced hypertension in the borderline hypertensive rat. Clin Sci (Lond) 59: 307-310, 1980.

LI J, BUKOSKI RD: Endothelium-dependent relaxation of hypertensive resistance arteries is not impaired under all conditions. Circ Res 72: 290-296, 1993.

LI J, BIAN KA, BUKOSKI RD: A non-cyclo-oxygenase, non-nitric oxide relaxing factor is present in resistance arteries of normotensive but not spontaneously hypertensive rats. Am J Med Sci 307: 7-14, 1994.

LÍSKOVÁ S, PETROVÁ M, KAREN P, KUNES J, ZICHA J: Influence of calcium-dependent potassium channel blockade and nitric oxide inhibition on norepinephrine-induced contractions in two forms of genetic hypertension. J Am Soc Hypertens 4: 128-134, 2010.

LÍŠKOVÁ S, PETROVÁ M, KAREN P, KUNEŠ J, ZICHA J: Effects of aging and hypertension on the participation of endothelium-derived constricting factor (EDCF) in norepinephrine-induced contraction of rat femoral artery. Eur J Pharmacol 667: 265-270, 2011.

LORKOWSKA B, BARTUS M, FRANCZYK M, KOSTOGRYS RB, JAWIEN J, PISULEWSKI PM, CHLOPICKI S: Hypercholesterolemia does not alter endothelial function in spontaneously hypertensive rats. $J$ Pharmacol Exp Ther 317: 1019-1026, 2006.

LOWRY OH, ROSEBROUGH NJ, FARR AL, RANDALL RJ: Protein measurement with the Folin phenol reagent. J Biol Chem 193: 265-275, 1951.

LÜSCHER TF, VANHOUTTE PM: Endothelium-dependent contractions to acetylcholine in the aorta of the spontaneously hypertensive rat. Hypertension 8: 344-348, 1986.

MANSI JA, DROLET G: Chronic stress induces sensitization in sympathoadrenal responses to stress in borderline hypertensive rats. Am J Physiol 272: R813-R820, 1997.

MAY JM: How does ascorbic acid prevent endothelial dysfunction? Free Radic Biol Med 28: 1421-1429, 2000.

MORI Y, OHYANAGI M, KOIDA S, UEDA A, ISHIKO K, IWASAKI T: Effects of endothelium-derived hyperpolarizing factor and nitric oxide on endothelial function in femoral resistance arteries of spontaneously hypertensive rats. Hypertens Res 29: 187-195, 2006.

MULVANY MJ, HALPERN W: Contractile properties of small arterial resistance vessels in spontaneously hypertensive and normotensive rats. Circ Res 41: 19-26, 1977.

PAULIS L, LÍSKOVÁ S, PINTÉROVÁ M, DOBESOVÁ Z, KUNES J, ZICHA J: Nifedipine-sensitive noradrenergic vasoconstriction is enhanced in spontaneously hypertensive rats: the influence of chronic captopril treatment. Acta Physiol (Oxf) 191: 255-266, 2007.

PAULIS L, ZICHA J, KUNES J, HOJNA S, BEHULIAK M, CELEC P, KOJSOVA S, PECHANOVA O, SIMKO F: Regression of L-NAME-induced hypertension: the role of nitric oxide and endothelium-derived constricting factor. Hypertens Res 31: 793-803, 2008.

PECHÁNOVÁ O, ZICHA J, PAULIS L, ZENEBE W, DOBESOVÁ Z, KOJSOVÁ S, JENDEKOVÁ L, SLÁDKOVÁ M, DOVINOVÁ I, SIMKO F, KUNES J: The effect of N-acetylcysteine and melatonin in adult spontaneously hypertensive rats with established hypertension. Eur J Pharmacol 561: 129-136, 2007.

PECHÁNOVÁ O, JENDEKOVÁ L, VRANKOVÁ S: Effect of chronic apocynin treatment on nitric oxide and reactive oxygen species production in borderline and spontaneous hypertension. Pharmacol Rep 61: 116-122, 2009.

PINTÉROVÁ M, KUNEŠ J, ZICHA J: Altered neural and vascular mechanisms in hypertension. Physiol Res 60: 381402, 2011.

PUZSEROVA A, BERNATOVA I: Chronic social stress increases nitric oxide-dependent vasorelaxation in normotensive rats. Interdiscip Toxicol 3: 109-117, 2010.

PÚZSEROVÁ A, CSIZMADIOVÁ Z, ANDRIANTSITOHAINA R, BERNÁTOVÁ I: Vascular effects of red wine polyphenols in chronic stress-exposed Wistar-Kyoto rats. Physiol Res 55: S39-S47, 2006.

PÚZSEROVÁ A, CSIZMADIOVÁ Z, BERNÁTOVÁ I: Effect of blood pressure on L-NAME-sensitive component of vasorelaxation in adult rats. Physiol Res 56: S77-S84, 2007.

PÚZSEROVÁ A, KOPINCOVÁ J, BERNÁTOVÁ I: Evidence for altered feedback regulation of nitric oxide synthesis in hypertensive rats. Physiol Res 59: 3P, 2010. 
PUZSEROVA A, SLEZAK P, BALIS P, BERNATOVA I: Long-term social stress induces nitric oxide-independent endothelial dysfunction in normotensive rats. Stress 16: 331-339, 2013.

RADAELLI A, MIRCOLI L, MORI I, MANCIA G, FERRARI AU: Nitric oxide dependent vasodilation in young spontaneously hypertensive rats. Hypertension 32: 735-739, 1998.

SANDERS BJ, LAWLER JE: The borderline hypertensive rat (BHR) as a model for environmentally-induced hypertension: a review and update. Neurosci Biobehav Rev 16: 207-217, 1992.

SHIMOKAWA H, YASUTAKE H, FUJII K, OWADA MK, NAKAIKE R, FUKUMOTO Y, TAKAYANAGI T, NAGAO T, EGASHIRA K, FUJISHIMA M, TAKESHITA A: The importance of the hyperpolarizing mechanism increases as the vessel size decreases in endothelium-dependent relaxations in rat mesenteric circulation. J Cardiovasc Pharmacol 28: 703-711, 1996.

STANKEVICIUS E, KEVELAITIS E, VAINORIUS E, SIMONSEN U: Role of nitric oxide and other endotheliumderived factors. Medicina (Kaunas) 39: 333-341, 2003.

TÖRÖK J: Participation of nitric oxide in different models of experimental hypertension. Physiol Res 57: 813-825, 2008.

TÖRÖK J, KRISTEK F: Functional and morphological pattern of vascular responses in two models of experimental hypertension. Exp Clin Cardiol 6: 142-148, 2001.

VANHOUTTE PM: Endothelial dysfunction: the first step toward coronary arteriosclerosis. Circ J 73: 595-601, 2009.

VANHOUTTE PM, FELETOU M, TADDEI S: Endothelium-dependent contractions in hypertension. Br J Pharmacol 144: 449-458, 2005.

VAPAATALO H, MERVAALA E, NURMINEN ML: Role of endothelium and nitric oxide in experimental hypertension. Physiol Res 49: 1-10, 2000.

VAZIRI ND, NI Z, OVEISI F, TRNAVSKY-HOBBS DL: Effect of antioxidant therapy on blood pressure and NO synthase expression in hypertensive rats. Hypertension 36: 957-964, 2000.

WEBB RC, VANDER AJ, HENRY JP: Increased vasodilator responses to acetylcholine in psychosocial hypertensive mice. Hypertension 9: 268-276, 1987.

YAMORI Y, OKAMOTO K: Spontaneous hypertension in rats versus essential hypertension in man. Singapore Med J 14: 393-394, 1973.

ZALBA G, BEAUMONT FJ, SAN JOSÉ G, FORTUÑO A, FORTUÑO MA, DÍEZ J: Is the balance between nitric oxide and superoxide altered in spontaneously hypertensive rats with endothelial dysfunction? Nephrol Dial Transplant 16: 2-5, 2001. 